\title{
The martyrdom of Saint Sebastian
}

\author{
M. Barale $\cdot$ F. Guaraldi
}

Received: 1 September 2014 / Accepted: 5 September 2014 / Published online: 21 November 2014

(C) Italian Society of Endocrinology (SIE) 2014

A Gothic fresco dating to the end of the fifteenth century and representing the martyrdom of Saint Sebastian has been recently discovered in the Church of St. Martin, a small medieval chapel in the northwestern town of Lignera (Cuneo, Italy).

Saint Sebastian is portrayed in the middle of the scene as a young, naked man pierced with arrows. A dwarf archer with coarse features and large goiter-all suggestive of cretinism—-stands on the left (Fig. 1a). The voluminous goiter, pierced by an arrow thrown by his companion (on the right), is highlighted by the presence of his hand placed over the bleeding wound (Fig. 1b).

It is well known how, at that time, congenital hypothyroidism (cretinism) and goiter were endemic in the surroundings of Cuneo, due to a lack of iodine in the environmental water [1].

As for other paintings, the goiter represents not only a physical deformity, but also the moral defacement of the archer, while the arrow running through it could symbolize the punishment for the crime committed.

Conflict of interest The authors declare that there are no conflicts of interest.
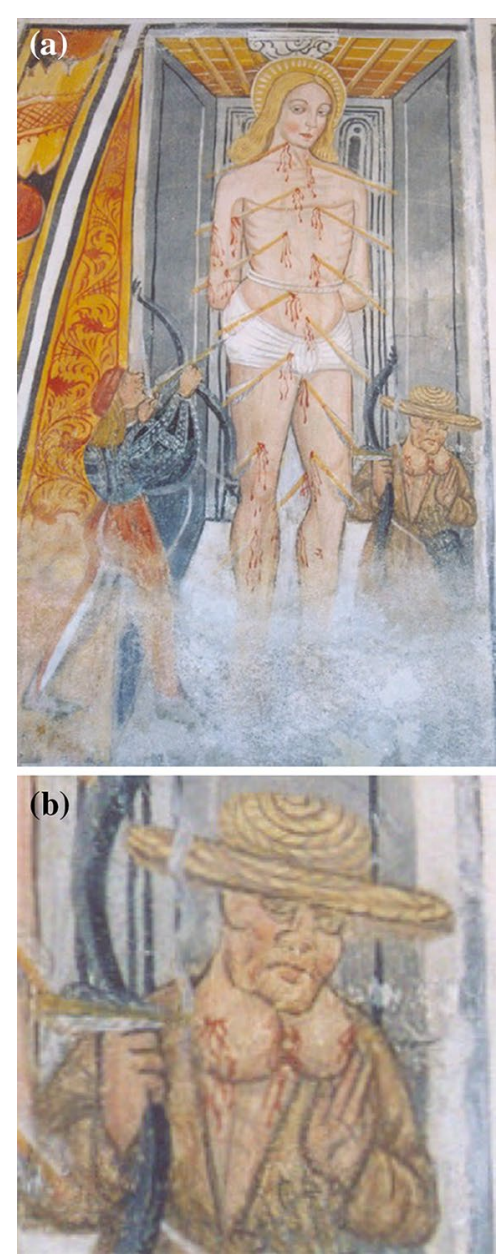

Fig. 1 a Gothic fresco representing the martyrdom of Saint Sebastian, $\mathbf{b}$ detail of the archer with goiter

\section{Reference}

1. Camanni F (2012) L'Endocrinologo 13(Suppl 5):2-12
Division of Endocrinology, Diabetology and Metabolism,

Department of Medical Sciences, University of Turin,

10126 Turin, Italy

e-mail: marco.barale@unito.it 